\title{
UNDERSTANDING THE LITERATURE ON PROBLEM ANALYSIS
}

\author{
Huynh, A.; McCahan, S. \\ Department of Mechanical and Industrial Engineering, University of Toronto, Ontario, Canada \\ albert.huynh@mail.utoronto.ca; mccahan@mie.utoronto.ca
}

\section{INTRODUCTION}

Problem analysis and problem solving, are frequently cited as integral to the skill set of engineering students and future engineers ${ }^{1}$. In engineering education, frameworks and strategies for problem solving are often misunderstood ${ }^{2}$ or poorly received by students. For this work, a framework or strategy is a defined process that is used to solve problems. To develop better instructional approaches for problem analysis and problem solving, particularly for application to open-ended or ill-structured problems, an awareness of the current practice in these strategies is necessary.

The focus of many problem solving frameworks is on cognition and not affect. Cognition refers to the storage and use of information by the learner. Cognitive considerations include providing clear steps to follow and enabling information creation through active learning. Affect refers to the attitudes and emotions experienced by the learner. Affective factors include student motivation to solve problems, tolerance for ambiguity, stress, and self-confidence. Psychological evidence on affective factors suggests strong impacts on the ability of students to solve problems ${ }^{3,4,5}$. This paper identifies a gap in the literature on the integration of affective factors into formal open-ended problem solving frameworks.

\section{PROBLEM PRESENTATION: PROBLEM-BASED LEARNING}

A common approach used in the current engineering pedagogy for open-ended or ill-structured problems is Problem-Based Learning (PBL). Although not a strategy for problem-solving in and of itself, PBL, and particularly a variant known as Project-Based Learning, have been widely used in engineering design courses. Both rely on the need for students to "pull" required information to solve a problem from the instructor or other sources rather than being given the information needed upfront ${ }^{6}$. This reflects both variants' use of a constructivist framework whereby students accrue the information and mental models that they need from multiple sources. Issues arise when students access the wrong information for the project at hand or develop unchallenged misconceptions. This is related to the ambiguity of both the problem framing and solution space. By comparison with well-structured problems that students are more familiar with, this ambiguity can cause confusion and frustration, decreasing motivation. The dissatisfaction and inability to deal with ambiguity in PBL and Project-Based Learning highlights a gap in students' affective training and mitigation abilities.

In Project-Based Learning, in addition to being assigned a selfdirected exploratory task, students may also be expected to balance aspects of project management including budgeting, scheduling, and team dynamics. The problems that are presented with this framing are often more authentic to the engineering design process, accentuating the benefits of situated learning theory. This realism is one way in which motivation (related to affect) is actually positively influenced by this approach $^{3,5}$. However, the heavy student workload often associated with PBL and its variants ${ }^{7,8}$ can potentially be a negative motivator against student engagement with the problem. Overall, as approaches, PBL and Project-Based Learning do create impacts on student affect, but neither is structured specifically to maximize it in a positive manner.

\section{INCREASING COMPLEXITY: DESIGN PROBLEMS}

Solving a design problem is often the problem solving component of Project-Based Learning approaches. Design problems are considered some of the most ill-structured amongst all problem types ${ }^{9}$, but given the requirements of the engineering profession, are critically important ${ }^{1}$.

In general, the overarching normative theories of design involve problem definition, specification definition, conceptual design, and detailed design stages ${ }^{3}$. None of these phases include directions or mitigation factors for student affect and focus purely on cognition.

These design strategy phases are often non-linear and iterative in nature as specifications change or new concepts are generated. Beyond the basic strategy, more complex problems are generally solved by "nesting" the basic problem solving process into a larger version of itself, effectively creating a number of smaller design problems ${ }^{3,10}$. With no affective mitigation, this complexity can create dissatisfaction in students who are used to a more linear work process.

Given the assertion that design problems are representative of openended cases in general, this process represents current state of illstructured problem solving within the engineering classroom where affective factors are not generally considered in the problem solving process.

\section{AFFECT AND MOTIVATION IN PROBLEM SOLVING}

Research has documented that aside from cognitive ability, affect plays a key role in solving problems. For example, the ability for students to contemplate the relevance of a problem to their broader academic careers or into their professional lives may be a good primer for committing to an otherwise daunting project ${ }^{5}$. Factors outside of cognitive skill alone are especially important in open-ended problems ${ }^{3,11}$.

There are some assertions that by alleviating cognitive load and providing students with a clear method to follow, that many of these traits (such as the initial distress of approaching an open-ended problem and lack of confidence in problem solving ability) are mitigated or accounted for $^{3,4}$. Various programs, however, have implemented techniques to address them separately, outside of the problem solving tasks themselves ${ }^{10}$. This supplementary approach may help to deal with affective factors generally but may not address them directly during the problem solving process.

The most established example in engineering education of a problem solving methodology that incorporates affective factors is the McMaster Problem Solving strategy. It discretely parses the traditional first phase of "understanding/defining the problem" into three parts, one of which is used to mentally and emotionally prepare a student for the remainder of the process ${ }^{10}$. Outside of this, the majority of frameworks follow the aforementioned design strategy focusing only on cognitive function.

The intentional consideration of affective factors in the design of problem solving strategies is a gap, that once filled, may help to advance the teaching in engineering education in a direction to enable students to better cope with the complexity and frustration that open-ended problems present.

\section{REFERENCES}

1. Engineers Canada, Canadian Engineering Accreditation

Board - Accreditation Criteria and Procedures. 2012.

Available at http://www.engineerscanada.ca/files/w_Accreditation_Crite ria_Procedures_2012.pdf, Accessed June 23, 2013.

2. Atman, C.J., Chimka J.R., Bursic, K.M. Results from a verbal protocol study of the design process. Frontiers in Education Annual Conference. 1997.

3. Jonassen, D.H. Learning to solve problems, New York, NY: Routledge; 2011.

4. Woods D.R. An evidence-based strategy for problem solving. J. for Eng. Educ. 2000:89(4):443-459

5. Ambrose, S. What factors motivate students to learn?. In How Learning Works. San Francisco, CA: Jossey-Bass; 2010:66-90. 6. Mills, E.J., Treagust, D.F. Engineering education - is problem-based or project-based learning the answer? Australasian J. for Eng. Educ. 2003. http://www.aaee.com.au/journal/2003/mills_treagust03.pdf. Accessed April 11, 2014.

7. Perrenet, J.C., Bouhuijs, P.A.J., Smits, J. The suitability of problembased learning for engineering education: theory and practice. Teaching in Higher Educ. 2000;5(3):345-358

8. Ribeiro, L.R.C. Electrical engineering students evaluate problembased learning (PBL). Intl. J. of Elec. Eng. Educ. 2008:45(2):152-161

9. Jonassen, D.H. Toward a design theory of problem solving. Educ. Tech. Research and Development, 2000:48(4):63-85

10. Woods D.R., et al. Developing problem solving skills: the McMaster problem solving program. J. for Eng. Educ. 1997:86(2):75-91

11. Schoenfeld, A.H., Learning to think mathematically: Problem solving, metacognition, and sense-making in mathematics. In D. Grouws, ed., Handbook for research on mathematics teaching and learning. New York, NY: Macmillan; 1992:334-370. 